\title{
Genetic Relatedness of Infectious Hypodermal and Hematopoietic Necrosis Virus Isolates, United States, 2019
}

Arun K. Dhar, Roberto Cruz-Flores, Janet Warg, Mary L. Killian, Andrew Orry, Jorge Ramos, Michelle Garfias, Gregory Lyons

Infectious hypodermal and hematopoietic necrosis virus (IHHNV) is a nonenveloped, linear, single-stranded DNA virus belonging to the family Parvoviridae and is a World Organisation for Animal Health (OIE)-notifiable crustacean pathogen. During screening of Penaeus vannamei shrimp from 3 commercial shrimp facilities in the United States for a panel of OIE-listed $(n=7)$ and nonlisted $(n=$ 2) crustacean diseases, shrimp from these facilities tested positive for IHHNV. Nucleotide sequences of PCR amplicons showed $99 \%-100 \%$ similarity to IHHNV isolates from Latin America and Asia. The whole genome of the isolates also showed high similarity to type 2 infectious forms of IHHNV. Phylogenetic analysis using capsid gene and whole-genome sequences demonstrated that the isolates clustered with an IHHNV isolate from Ecuador. The detection of an OIE-listed crustacean pathogen in the United States highlights the need for biosecurity protocols in hatcheries and grow-out ponds to mitigate losses.

$\mathrm{T}$ he Penstylhamaparvovirus species Decapod penstylhamaparvovirus 1, commonly known as infectious hypodermal and hematopoietic necrosis virus (IHHNV), is the smallest of known shrimp viruses belonging to the family Parvoviridae, subfamily Hamaparvovirinae $(1,2)$. The virions are icosahedral, nonenveloped, measure $22-23 \mathrm{~nm}$ in size, and contain a single-stranded DNA genome $\approx 4.1 \mathrm{~kb}$ in length $(3,4)$.

IHHNV was first reported in juveniles and subadults of blue shrimp (Penaeus stylirostris) in Hawaii in the early 1980s and caused mass deaths (5). The

Author affiliations: The University of Arizona, Tucson, Arizona, USA (A.K. Dhar, R. Cruz-Flores, J. Ramos, M. Garfias, G. Lyons); US Department of Agriculture National Veterinary Services Laboratories, Ames, lowa, USA (J. Warg, M.L. Killian); Molsoft, Inc., San Diego, California, USA (A. Orry)

DOI: https://doi.org/10.3201/eid2802.211874 virus also caused large-scale deaths in blue shrimp in Mexico (6). The virus outbreak in P. stylirostris shrimp in Mexico in the early 1980s led to a transition in the captive breeding program from a more susceptible and physically larger shrimp species, $P$. stylirostris (a preferred cultured species in the mid1980s), to the smaller but more tolerant $P$. vannamei shrimp (7). In the black tiger shrimp (P. monodon), another economically vital species, IHHNV is reported to cause asymptomatic infection and deformities $(4,8)$. In a recent study, a farm-level IHHNV infection resulted in reduced growth performance, a higher food-conversion ratio, and a lower survival rate, which led to a production loss of approximately US $\$ 67,000$ per hectare of farm gate value when ponds were stocked with IHHNV-infected postlarvae having high viral load compared with postlarvae with low viral load (9). This finding suggests that IHHNV remains an economically relevant viral pathogen in shrimp aquaculture.

Most of the genetic lines of P. vannamei shrimp farmed in Latin America and Asia today are claimed to be tolerant or resistant to the virus, and IHHNV is assumed to have no ill effect on the production parameters in these shrimp lines, although scientific evidence to support this assumption is lacking. Considering these genetic lines can tolerate high levels of IHHNV without displaying clinical manifestations of the disease, transboundary movement of shrimp broodstock and larvae from these lines might lead to widespread distribution of IHHNV unless rigorous biosecurity is practiced in hatcheries. Routine disease surveillance that adheres to the US Department of Agriculture and World Organisation for Animal Health (OIE) guidelines and diagnostics performed by the Aquaculture Pathology Laboratory (APL) and the National Veterinary Services 
Laboratories (NVSL) have helped to mitigate the spread of major pathogens in the United States. This success is reflected by the 26-year absence of the virus from all US-based farms until now.

During June 2019, P. vannamei shrimp samples from broodstock and postlarvae originating in commercial shrimp facilities in Texas and Florida were submitted to the APL at the University of Arizona for routine screening for viral, bacterial, and fungal pathogens. IHHNV was the only pathogen identified in shrimp from both facilities. Trace testing resulted in additional IHHNV-positive animals. We further characterized the IHHNV strains detected in the United States by genome sequencing and determined their genetic similarities to other IHHNV strains. Considering the history of economic losses caused by IHHNV over the past 4 decades, the recent detection of IHHNV in commercial facilities in the United States highlights the need to enhance biosecurity to prevent spread and future disease outbreaks caused by IHHNV or other diseases in shrimp aquaculture. The need to further enhance diagnostic testing and biosecurity measures was underscored by the subsequent detection of IHNNV in the United Kingdom and Canada, which was directly linked to commercial shrimp facilities in the United States $(10,11)$. The objectives of this study were to elucidate the genomic characteristics of the virus to ensure that the IHHNV isolate is an infectious form of the virus and not a genome-integrated form, as well as to determine its genetic relatedness to IHHNV isolates described in the literature.

\section{Materials and Methods}

\section{Sample Submission}

Samples of $P$. vannamei shrimp were collected from commercial shrimp facilities, 2 in Texas (case nos. 19428 and 19-644) and 1 in Florida (case no. 19-490) and submitted to the University of Arizona APL. Samples from case no. 19-428 consisted of 6 vials containing shrimp pleopods and postlarvae preserved in ethanol. Case no. 19-644 consisted of 4 bags of frozen whole shrimp. Case no. 19-490 consisted of pleopods in ethanol. We collected representative samples $(\approx 30$ $\mathrm{mg}$ ) for nucleic acid extraction. Samples testing positive for IHHNV at the University of Arizona were submitted to the NVSL (Ames, Iowa, USA) for confirmation and further characterization.

\section{Nucleic Acid Extraction and PCR}

We extracted total nucleic acid from pools of pleopods and whole postlarvae (case nos. 19-428 and 19-490). For case no. 19-644, in which whole animals were submitted, we extracted total nucleic acid from tail muscle tissues (for screening systemic pathogens) or hepatopancreas (for screening enteric pathogens) by using the Maxwell 16 Cell LEV DNA and RNA Purification Kits (Promega, https:/ / www. promega.com) or using the Maxwell 16 Instrument configured with LEV Hardware, according to manufacturer instructions.

We used pleopod DNA to screen for IHHNV (12), IHHNV-related genome-integrated sequence (13), and white spot syndrome virus (14). We used hepatopancreas DNA for PCR screening of Baculovirus penaei (according to an in-house method), necrotizing hepatopancreatitis bacterium (15), Enterocytozoon hepatopenaei (16), and acute hepatopancreatic necrosis disease (17). We evaluated pleopod and tail muscle RNA by using reverse transcription PCR tests for yellow head virus (18), Taura syndrome virus (19), and infectious myonecrosis virus (20). For all reactions, we used $1 \mu \mathrm{L}$ of nucleic acids at a concentration range of $1-50 \mathrm{ng} / \mu \mathrm{L}$.

We performed testing for IHHNV first by using the OIE-recommended $389 \mathrm{~F} / \mathrm{R}$ primer pair, followed by the $309 \mathrm{~F} / \mathrm{R}$ primer pair to detect the presence of the infectious form of IHHNV (13). We visualized PCR products on a $1.5 \%$ agarose gel to confirm presence of viral DNA. We used DNA from samples testing positive for IHHNV by PCR screening to amplify the nonstructural (NS1) and capsid protein $(\mathrm{CP})$ genes. We amplified the NS1 gene by using 2 sets of primers to generate 2 amplicons with a 66-bp overlap (Table 1) and the CP gene by using the method of Robles-Sikisaka et al. (21), which yields a 1,088-bp amplicon.

\section{Sanger Sequencing and Data Analysis}

We column purified PCR amplicons by using the GeneJET PCR Purification Kit (ThermoFisher Scientific, https://www.thermofisher.com) according to manufacturer instructions. Purified PCR products were submitted to the University of Arizona Genetics Core for Sanger sequencing (Table 2). We aligned sequence data in Geneious Prime to generate a consensus sequence (22) and compared those sequences with published genomes using BLASTn (23).

\section{Whole-Genome Sequencing and Bioinformatics Analyses}

We extracted total nucleic acids from tissue homogenates for initial testing by using the MagMAX-Ambion kit 1836 on an automated MagMAX Express magnetic particle processor (ThermoFisher Scientific). We extracted additional DNA from tissue homogenates 
Table 1. Primers used for the detection of the IHHNV genome in commercially raised Penaeus vannamei shrimp, Texas and Florida, United States, 2019*

\begin{tabular}{|c|c|c|c|c|}
\hline Target gene & Primer name & Sequence, $5^{\prime} \rightarrow 3^{\prime}$ & Amplicon size, bp & Reference \\
\hline NS1 & $389 \mathrm{~F}$ & CGGAACACAACCCGACTTTA & 389 & (13) \\
\hline NS1 & 389R & GGCCAAGACCAAAATACGAA & & \\
\hline NS1 & IHHNV-309F & TCCAACACTTAGTCAAAACCAA & 309 & (13) \\
\hline NS1 & IHHNV-309R & TGTCTGCTACGATGATTATCCA & & \\
\hline NS1 (Left) & 159_IH_NS1_S & AACTGACGAGTGAAGAGGCT & 1295 & This study \\
\hline NS1 (Left) & 1446_IH_NS1_AS & GTGTCCGGAGTATGTGATGT & & This study \\
\hline NS1 (Right) & 1400_IH_NS1_S & GGACGAACGCCAAACTTCAC & 1313 & This study \\
\hline NS1 (Right) & 2698_IH_NS1_AS & ATCTGTGTGGGTCTGGTCC & & This study \\
\hline $\mathrm{CP}$ & $\mathrm{CP} 1 \mathrm{~F}$ & GATCACCAGCACGACTTCCT & 1088 & $(21)$ \\
\hline $\mathrm{CP}$ & CP2R & CGGGTATATATTGCACATCGAA & & \\
\hline
\end{tabular}

treated with Benzonase to reduce host DNA by using the DNeasy Blood and Tissue Kit (QIAGEN, https:// www.quiagen.com). We prepared libraries by using the Ion Xpress Plus Fragment Library Kit (ThermoFisher Scientific) according to manufacturer instructions and templates by using the Ion 520 on the Ion Chef System, then sequenced by using an Ion 520 Chip on the Ion S5 System (ThermoFisher Scientific). We performed reference-based mapping (GenBank accession no. NC_002190) by using SeqMan NGen version 14 (DNASTAR, https://www.dnastar.com) with default parameters for automatic read trimming and assembly and verified alignments resulting in the final consensus sequence. The genomes (minus ends because random priming was used) of IHHNV from Texas and Florida were deposited in GenBank (accession nos. MN968717.1 and MN968716.1).

\section{Phylogenetic Analyses}

Initially, we inferred the phylogenetic analysis by using the neighbor-joining method (24) for the CP gene of IHHNV with 1,000 bootstraps. The tree was drawn to scale; branch lengths were in the same units as those of the evolutionary distances used to infer the phylogenetic tree. We computed the evolutionary distances (base substitutions per site) by using the maximum composite likelihood method (25). This analysis involved $32 \mathrm{nt}$ sequences. All ambiguous positions were removed for each sequence pair (pairwise deletion option). A total of 995 positions were represented in the final dataset. We conducted evolutionary analyses in MEGA X (25).

We downloaded all available complete genomes from GenBank on November 1, 2019, for phylogenetic analysis. We inferred evolutionary history by using the maximum-likelihood method based on the Tamura-Nei model (24). We obtained initial tree(s) for the heuristic search automatically by applying neighbor-joining and BioNJ algorithms to a matrix of pairwise distances estimated by using the maximum-likelihood approach and then by selecting the topology with superior log likelihood value. The tree is drawn to scale; branch lengths are measured in the number of substitutions per site. The analysis involved $28 \mathrm{nt}$ sequences. Codon positions included were $1 s t+2 n d+3 r d+$ Noncoding. We eliminated all

\begin{tabular}{|c|c|c|}
\hline Target gene & Primer name & Sequence, $5^{\prime} \rightarrow 3^{\prime}$ \\
\hline NS1 & 159_IH_NS1_S & AAC TGA CGA GTG AAG AGG CT \\
\hline NS1 & $1446^{-} \mathrm{IH}^{-} \mathrm{NS} 1^{-} \mathrm{AS}$ & GTG TCC GGA GTA TGT GAT GT \\
\hline NS1 & 482_I IH HN V V_NS̄1_S & CCC CAA CAA ATA TCG CTG CG \\
\hline NS1 & 511_IHHNV_NS1_S & AGA TCA CAT TCT ACC GTG GTG \\
\hline NS1 & 342_IH_NS1_Seq_AS & ACTT GTA CTT ACA TTT GTA T \\
\hline NS1 & 1400_IH_N̄S1_S & GGA CGA ACG CCA AAC TTC AC \\
\hline NS1 & 2627_IH_NS̄1_Séq_S & CAA GCC CAA GGA AAA GAT CC \\
\hline NS1 & $\overline{2} 3 \overline{90}$ CP_S & CTA CTG GGT ACC ACC AGC \\
\hline NS1 & 2698 IH_NS1_AS & ATC TGT GTG GGT CTG GTC C \\
\hline NS1 & 2540 IH_CP_S & AGG CCT CTT CCA AGA ATA CG \\
\hline NS1 & 2682 IHHNV_NS̄1_AS & ACT TGA TCC TTC GGC GTG TT \\
\hline NS1 & 2540 IH_CP_S & AGG CCT CTT CCA AGA ATA CG \\
\hline NS1 & 2682 IHHNV_NS1_AS & ACT TGA TCC TTC GGC GTG TT \\
\hline NS1 & IHHNV-1942_F & GTC ACT AAT TAC AAA CCT GCA G \\
\hline NS1 & IHHNV-2020R & GCA TAT TGT CGT AGT CTG GT \\
\hline $\mathrm{CP}$ & IHHNV-CP_S & ATG TGC GCC GAT TCA ACA AG \\
\hline $\mathrm{CP}$ & IH_CP_Seq_S & САТ ААТ САА СТА ТСА АСТ АA \\
\hline $\mathrm{CP}$ & IH_CP_Seq_AS & TGC CAA TGT TAC GTC GGT TTC C \\
\hline
\end{tabular}


positions containing gaps and missing data. A total of 2,368 positions were represented in the final dataset. We conducted evolutionary analyses in MEGA7 (25).

\section{Predicted Tertiary Structure of IHHNV CP}

We performed all molecular modeling by using ICMPro desktop modeling software version 3.8 (MolSoft LLC, https://www.molsoft.com). Homology models of the CP gene of the IHHNV Texas isolate (case no. 19-428) and Florida isolate (case no. 19-490) were built by using the crystal structure of Decapod penstylhamaparvovirus $1 \mathrm{CP}$ as a template (PDB code 3N7X) (26). First, we built a sequence alignment that demonstrated the amino acid sequences have very high homology (88\%). Considering that the Texas isolates (case nos. 19-428 and 19-644) had identical amino acid sequences, we used only 1 for the analysis. The amino acid sequence of the isolates was then threaded onto the backbone of the full biomolecule capsid template structure by using ICM-Pro, and the model was energy minimized.

\section{Results}

\section{Detection of IHHNV in Shrimp Hatchery- and Field-Collected Samples from Texas and Florida}

We detected IHHNV in samples from Texas (case nos. 19-428 and 19-644) and Florida (case no. 19490) by using the OIE-recommended conventional PCR-based diagnostic method (12) (Figure 1). These results confirmed the first detection of the virus in 2 commercial aquaculture facilities in the United States since 1993 (27).

\section{Amplification and Sequencing of $\mathrm{CP}$ and NS1 Genes of IHHNV}

The complete CP and NS1 genes of the IHHNV isolates from Texas and Florida were successfully amplified in overlapping fragments. The 2 amplicons together represent $\approx 88 \%$ of total length of IHHNV genome. We sequenced the NS1 and CP amplicons of both Texas and Florida IHHNV isolates. BLAST analysis demonstrated that both genes showed highest similarity to homologous genes of the IHHNV Ecuador strain (GenBank accession no. AY362548.1) (Table 3).

\section{Whole-Genome Sequencing of IHHNV Texas and Florida Isolates}

For isolate 19-490 from Florida, 22,166 sequences were assembled to generate a consensus sequence $3749 \mathrm{bp}$ in length with a median depth of coverage of $1,036 \times$. For isolates 19-428 and 19-644 from Texas, 118,348 sequences were assembled to generate a consensus sequence of 3,750 bp in length with a median depth of coverage of $5,825 \times$. Consensus sequences represent the complete coding region of the virus. The 2 isolates shared $99.71 \%$ sequence identity. Furthermore, the sequences had $99.44 \%$ (Texas) and 99.52\% (Florida) identity to IHHNV from Ecuador.

\section{Phylogenetic Analysis}

Phylogenetic analysis using only the $\mathrm{CP}$ gene sequences showed that IHHNV from both Texas and Florida formed a highly supported cluster with the Ecuador strain of IHHNV. This cluster represents the type 2 infectious form of IHHNV (Figure 2). The IHHNV in this cluster infect penaeid species including $P$. vannamei, $P$. stylirostris, and P. monodon shrimp. In the neighbor-joining phylogenetic tree, the type 3 clade is represented by IHHNV isolates from India, Tanzania, Madagascar, and Australia. These strains infect $P$. monodon shrimp, are noninfectious, and remain integrated into the $P$. monodon genome. The third genotype, type 1 , is represented by isolates from the Philippines and Thailand that infect both P. monodon and $P$. vannamei shrimp. Whole-genome phylogeny showed equivalent results (tree not shown).

\section{Predicted Tertiary Structure of CP of Texas and Florida IHHNV Isolates}

The IHHNV Texas and Florida viruses detected have $\approx 88 \%$ amino acid sequence identity with the crystal structure of Penaeus stylirostris densovirus (PstDNV) capsid (PDB code 3N7X) (Figure 3, panel A). The crystal structure of PstDNV was determined to $2.5-\AA$ resolution by x-ray crystallography and based on 299 out of 329 aa of capsid protein missed $30 \mathrm{~N}^{\prime}$-terminal aa (26) (Figure 3, panel B). Because of the high sequence similarity, the modeled structure showed key $\beta$-barrel motifs that are hallmarks of many icosahedral viruses.

\section{Discussion}

During routine disease surveillance, 3 Pacific white shrimp ( $P$. vannamei) samples from 2 facilities in Texas and 1 facility in Florida tested positive for IHHNV. The samples were initially screened according to the OIE-recommended PCR protocol using the primer pair IHHNV $389 \mathrm{~F} / \mathrm{R}$ (13). The results were further confirmed by using primer pair IHHNV $309 \mathrm{~F} / \mathrm{R}$. The amplicons $389 \mathrm{bp}$ and $309 \mathrm{bp}$ from all 3 cases were sequenced by Sanger methods; the nucleotide sequence of these amplicons showed a 99\% identity with previously reported IHHNV sequences deposited in GenBank. Confirming the presence of IHHV by 

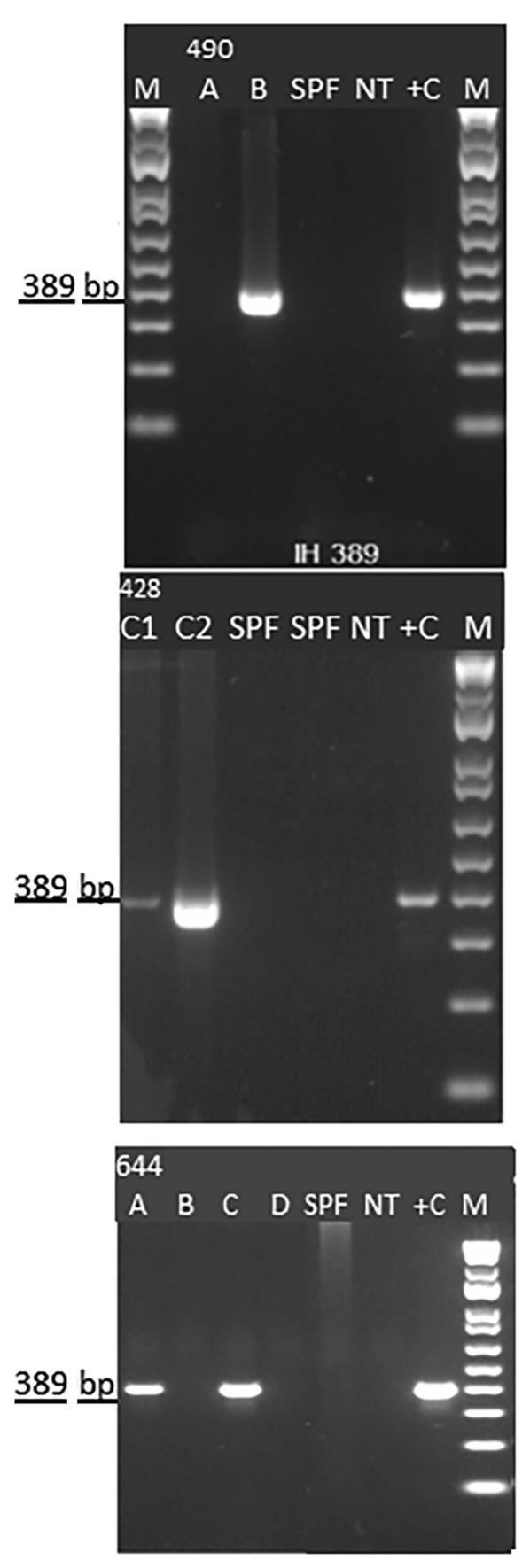
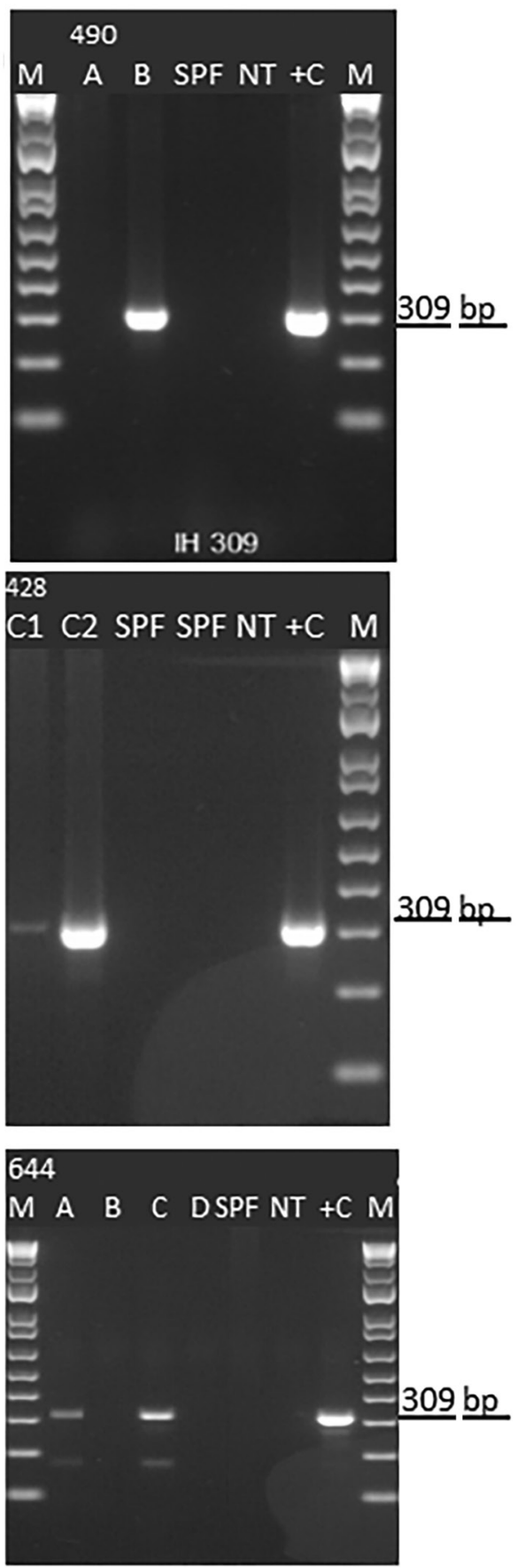

Figure 1. Detection of infectious hypodermal and hematopoietic necrosis virus (IHHNV) in Penaeus vannamei shrimp from the United States by conventional PCR, 2019. Agarose gel photographs show 389-bp IHHNV-specific amplicon (left column) and 309-bp IHHNVspecific amplicon (right column).

Top row represents case number 19-490, P. vannamei broodstock samples originating in Florida ( $A$ and $B$ ). Middle row represents case number 19428, $P$. vannamei post-larvae samples originating in Texas (C1 and $\mathrm{C} 2$ ). Bottom row represents case number 19-644, frozen $P$. vannamei shrimp originating from an indoor farm in Texas (A, $B, C$, and D). Lane $M, 100-b p$ molecular weight marker (New England Biolabs, Inc., https:// www.neb.com); lane SPF, specific pathogen-free $P$. vannamei shrimp; lane NT, no template control; lane $+\mathrm{C}$, positive control for PCR.
PCR and genome sequencing is needed for diagnostic certainty, because genome-integrated sequences of IHHNV have been shown to be present in P. monodon and $P$. vannamei shrimp $(13,28)$. Because IHHNV is an OIE-listed disease, once the virus was detected at the APL, an aliquot of all the nucleic acid and tissue samples was sent to the NVSL (Ames, Iowa, USA) for confirmation and further characterization. Under this testing scheme performed by APL and NVSL,
IHHNV has been successfully kept at bay from USbased broodstock and hatchery operations for more than 2 decades. This recent detection, however, shows that stringent surveillance is needed to ensure facilities are free of disease before broodstock and larvae are moved across countries and continents.

The IHHNV genome contains 2 overlapping open reading frames encoding the nonstructural proteins NS1 and NS2 and a third open reading frame that 
Table 3. Sequence similarity of CP and NS-1 genes of Texas and Florida IHHNV isolates to IHHNV Ecuador strain, 2019*

\begin{tabular}{|c|c|c|c|c|}
\hline Case no. & CP identity, \% & NS1 identity, $\%$ & Strain & GenBank accession no \\
\hline $19-428-\mathrm{C} 2$ & 99.36 & 99.06 & Ecuador & AY362548.1 \\
\hline $16-490-B$ & 99.72 & 99.69 & Ecuador & AY362548.1 \\
\hline $19-644-A$ & 99.36 & 99.65 & Ecuador & AY362548.1 \\
\hline $19-644-C$ & 99.36 & 99.65 & Ecuador & AY362548.1 \\
\hline
\end{tabular}

encodes the viral capsid protein $(3,4,7)$. Together, these 3 gene segments comprise $\approx 88 \%$ of the complete genome. In this study, after IHHNV was detected in the 3 samples, the CP (990 bp) and NS1 (2440 bp) genes were amplified and sequenced. Subsequently, the near full-length genome of 2 isolates originating from 2 shrimp facilities in Texas and Florida were sequenced by using next-generation sequencing, generating contigs of 3,750 bases in length for the Texas isolates and 3,749 bases in length for the Florida isolates. All 3 cases (19-428, 19-490, and 19-644) had high sequence identity (99\%) among them, as well as to an IHHNV isolate originating in Ecuador (GenBank accession no. AY362548.1). In 2003, two genotypes of IHHNV were described. At that time, type 1 strains were found in the Americas and East Asia (primarily the Philippines), and type 2 strains were detected in Southeast Asia (29). Since then, an additional genotype, type 3, has been described, and the geographic range of type 1 and type 2 viruses has spread worldwide. Phylogenetic

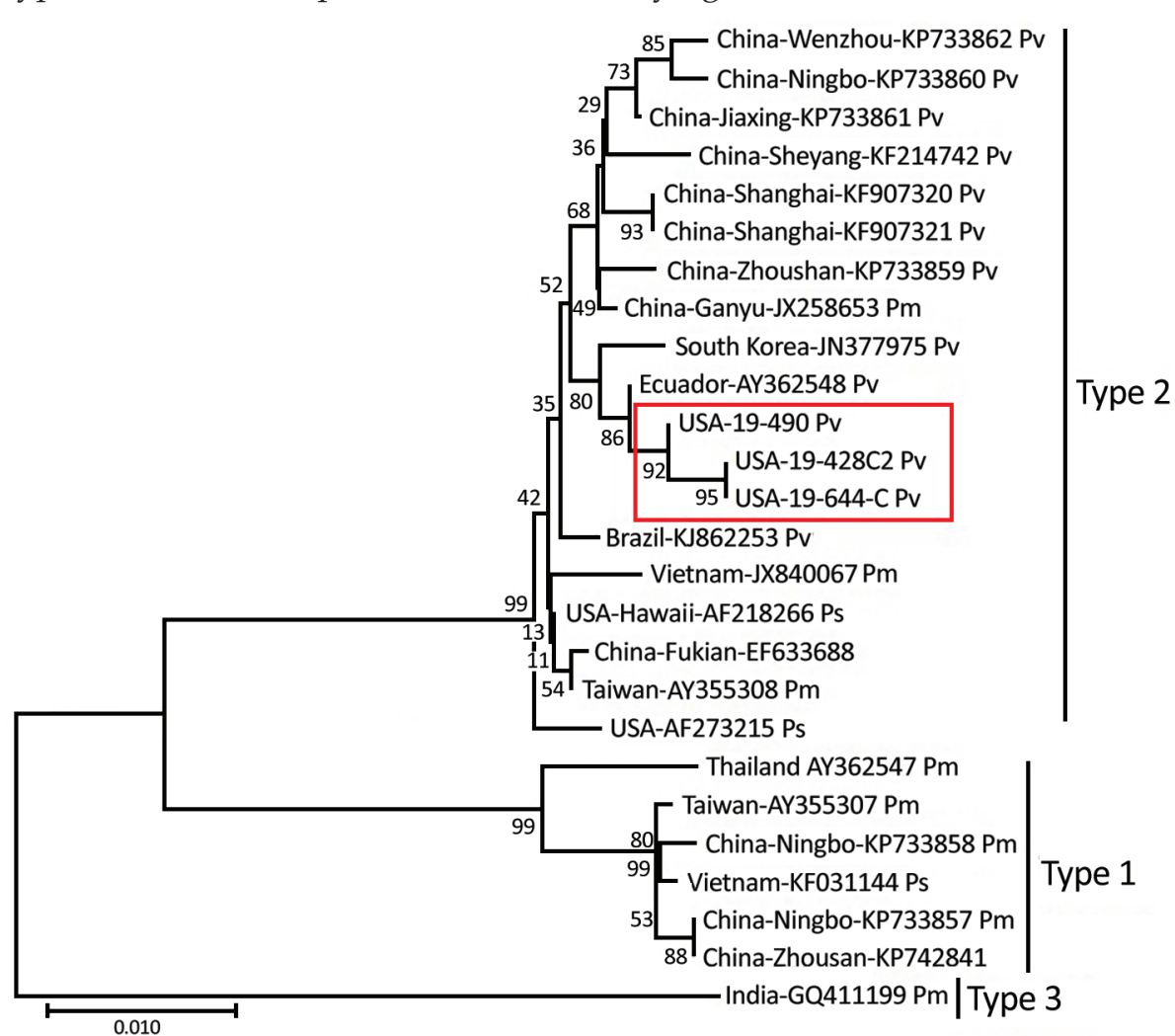

analysis using the CP gene and full-length genomes indicate the recently detected IHHNV viruses from the United States form a strongly supported cluster with type 2 strains from the Americas. These strains represent the infectious forms of IHHNV and are clearly distinct from type 1 (infectious) and type 3 (noninfectious). (Figure 2). Since the virus was first described in the early 1980s, <50 complete genomes have been published in GenBank, and many of the genomes have incomplete metadata, including date of isolation or detection, which confounds interpretation of phylogenetic analysis. The lack of these critical pieces of information limits the ability to infer transmission of the virus on the basis of phylogeny alone. Epidemiologic information for the Texas isolates and the phylogenetic analysis suggest a link between the detections of IHHNV in Texas and Florida, supporting their close genetic relationship.

The close similarity at the whole-genome level and the phylogenetic data indicate that all sequences derive from a strain from Ecuador, suggesting a
Figure 2. Evolutionary relationships of the infectious hypodermal and hematopoietic necrosis virus (IHHNV) strains (19-428, 19-490, and 19-644) recently detected in the United States and published capsid protein gene sequences. The recent IHHNV strains (red box) fall into the type 2 lineage. The evolutionary history was inferred by using the neighbor-joining method (24). The optimal tree with the sum of branch length $=0.20086053$ is shown. The percentage of replicate trees in which the associated taxa clustered together in the bootstrap test $(1,000$ replicates) are shown next to the branches. The tree is drawn to scale, with branch lengths in the same units as those of the evolutionary distances used to infer the phylogenetic tree. The evolutionary distances were computed by using the maximumlikelihood method (25). Based upon full-genome phylogenetic analysis, the Texas and Florida IHHNV viruses appear to be related to a strain from Ecuador (GenBank accession no. AY362548.1). Scale bar indicates substitutions per site. 

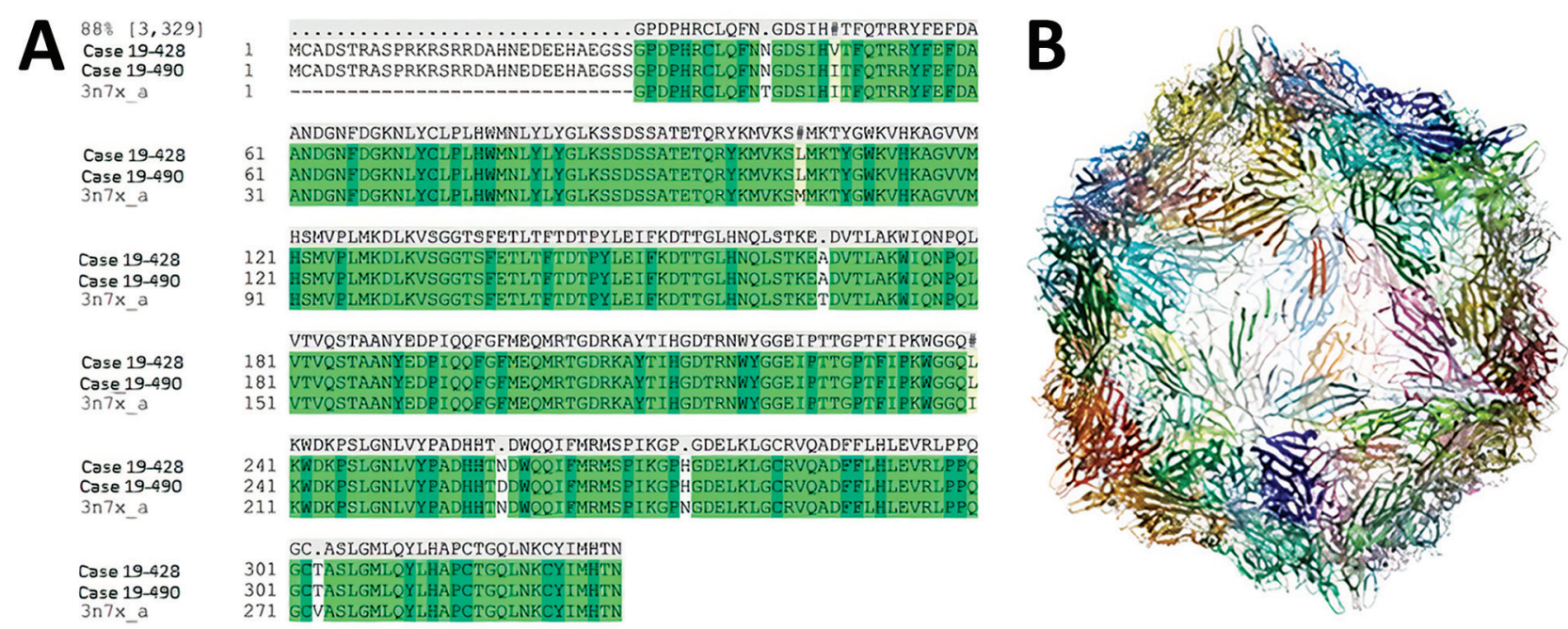

Figure 3. Alignment and structure of infectious hypodermal and hematopoietic necrosis virus (IHHNV) strains recently detected in Texas (19-428) and Florida (19-490), USA. A) Multiple alignment of amino acid sequence based on translation of the capsid protein gene of isolates with Penaeus stylirostris densovirus capsid protein sequence (PDB code 3N7X). B) Predicted tertiary structure of the isolates from Texas and Florida.

common origin for both Texas and Florida strains. This occurrence is not uncommon in shrimp aquaculture; other viral pathogens such as Taura syndrome virus and infectious myonecrosis virus have been traced back to their original source $(30,31)$. The transboundary movement of shrimp has gone hand-inhand with the expansion of shrimp farming and will not cease anytime soon. Investment in newer, more sensitive diagnostic methodologies based on CRISPR, digital droplet PCR, and next-generation sequencing approaches could help limit the spread of pathogens $(32,33)$. In addition, rigorous screening of animals for IHHNV and other pathogens is necessary to make moving shrimp safer and thereby make the industry more sustainable and resilient in the long run. This rigorous screening would entail collaborative efforts between shrimp producers, diagnostic and research institutions, and corresponding government entities.

To determine whether the predicted amino acid sequences of the IHHNV capsid protein from Texas and Florida isolates can conform an icosahedral symmetry, homology modeling was performed with a reference tertiary structure of another IHHNV isolate, PstHPV-1, for which a crystal structure is available in the Protein Data Bank (PDB code 3N7X). Although a sequence identity of $88 \%$ between the reference strains and US strains might seem low, this identity is because of the absence of 20 aa from the $\mathrm{N}^{\prime}$-terminal of the reference strain. The analysis of the same sections (excluding the first 20 aa from the $\mathrm{N}^{\prime}$-terminal of US strains) of the CP of the 3 strains demonstrates a sequence identity of $97.5 \%$. The tertiary structure showed that IHHNV Texas and Florida isolates can conform an icosahedral symmetry, as expected for a parvovirus infectious virion (26). Thus, the predicted tertiary structure analysis supports the phylogenetic data that IHHNV Texas and Florida isolates represent an infectious form of the virus and not a type 3 strain.

Although it might seem redundant at first sight to perform protein modeling, we considered it fundamental for the study to confirm the capsid protein coding regions were not endogenous viral elements (EVEs). These EVEs are well characterized in P. monodon shrimp, but they have not been reported as frequently in P. vannamei shrimp. Furthermore, the EVEs from $P$. vannamei shrimp might contain regions of the IHHNV genome that are different to the regions reported in $P$. monodon shrimp. Because of the lack of frozen shrimp samples, we could not delineate the pathogenicity of the virus in experimental bioassay, and hence could not perform histopathology to assess cellular manifestation of the viral infection; the in silico analysis of IHHNV capsid protein data gave further confidence that these strains represented an infectious form of IHHNV and not an EVE. A combination of protein modeling, whole-genome sequencing, PCR, and phylogenetic analysis are complementary in nature and sufficient to deem the IHHNV strain detected in the United States in 2019 an infectious type 2 strain of the virus.

IHHNV is well known to be endemic in shrimpproducing countries in the Americas, Asia, and Australia (7). IHHNV is also well established in wild shrimp populations in the Gulf of Mexico (21). In 
the United States, however, the virus had not been reported in farmed shrimp since 1993 (27). Over the past 4 decades, as shrimp farming evolved from subsistence levels of farming to an intensive culture system worldwide, infectious diseases have emerged and spread regularly. The spread of diseases has been further exacerbated by the movement of broodstock and post-larvae across countries and continents. The movement of infected shrimp has played a critical role in the spread of pathogens like white spot syndrome virus, Taura syndrome virus, and IHHNV (34). The origin of the IHHNV isolates described in this study remains unknown, but the data suggest these isolates could have originated in Latin America. This finding highlights the need to keep following strict biosecurity protocols, including disease surveillance in shrimp hatcheries and grow-out ponds, to prevent further introduction of IHHNV or other OIE-listed and nonlisted pathogens in shrimp facilities in the United States and elsewhere.

\section{Acknowledgments}

We would like to thank Jasmine Millabas, Tiffany Bledsoe, Gwendolyn Mioduszewska, Angela Cruz, and Kerrie Franzen for their aid in sample processing and molecular procedures.

Funding for this research was provided by the Aquaculture Pathology Laboratory Disease Diagnostic Fund. Partial funding was provided by the College of Agriculture \& Life Sciences of The University of Arizona to A.K.D.

\section{About the Author}

Dr. Dhar is an associate professor and director of the Aquaculture Pathology Laboratory in the School of Animal and Comparative Biomedical Sciences, University of Arizona, Tucson, Arizona, and an OIE Expert of Crustacean Diseases. His expertise involves developing diagnostics, oral vaccines, and therapies against infectious diseases in shrimp and fin fish.

\section{References}

1. Tijssen P, Agbandje-McKenna M, Almendral J, Bergoin M, Flegel T, Hedman K, et al. Parvoviridae. In: Murphy FA, Fauquet C, Bishop D, editors. Virus taxonomy: ninth report of the international committee on taxonomy of viruses. Amsterdam: Elsevier; 2012. p. 405-25.

2. Pénzes JJ, Pham HT, Chipman P, Bhattacharya N, McKenna R, Agbandje-McKenna M, et al. Molecular biology and structure of a novel penaeid shrimp densovirus elucidate convergent parvoviral host capsid evolution. Proc Natl Acad Sci U S A. 2020;117:20211-22. https:/ / doi.org/ $10.1073 /$ pnas. 2008191117

3. Shike H, Dhar AK, Burns JC, Shimizu C, Jousset FX, Klimpel KR, et al. Infectious hypodermal and hematopoietic necrosis virus of shrimp is related to mosquito brevidensoviruses. Virology. 2000;277:167-77. https://doi.org/ 10.1006/viro.2000.0589

4. Dhar AK, Robles-Sikisaka R, Saksmerprome V, Lakshman DK. Biology, genome organization, and evolution of parvoviruses in marine shrimp. In: Advances in virus research, 1st ed. Amsterdam: Elsevier Inc.; 2014. p. 85-139.

5. Lightner DV, Redman RM, Bell T, Brock J. Detection of IHHN virus in Penaeys stylirostris and P. vannamei imported into Hawaii. J World Maric Soc. 1983;225:212-25.

6. Bell TA, Lightner DV. IHHN virus: Infectivity and pathogenicity studies in Penaeus stylirostris and Penaeus vannamei. Aquaculture. 1984;38:185-94. https:/ / doi.org/ 10.1016/0044-8486(84)90142-X

7. Dhar AK, Cruz-Flores R, Caro LFA, Siewiora HM, Jory D. Diversity of single-stranded DNA containing viruses in shrimp. Virusdisease. 2019;30:43-57. https:// doi.org/ 10.1007/s13337-019-00528-3

8. Flegel TW. Detection of major penaeid shrimp viruses in Asia, a historical perspective with emphasis on Thailand. Aquaculture. 2006;258:1-33. https://doi.org/10.1016/ j.aquaculture.2006.05.013

9. Sellars MJ, Cowley JA, Musson D, Rao M, Menzies ML, Coman GJ, et al. Reduced growth performance of black tiger shrimp (Penaeus monodon) infected with infectious hypodermal and hematopoietic necrosis virus. Aquaculture. 2019;499:160-6. https:// doi.org/10.1016/ j.aquaculture.2018.09.032

10. Centre for Environment Fisheries and Aquaculture Science. International database on aquatic animal disease: infectious hypodermal and haematopoietic necrosis, United Kingdom [Immediate notification 20/08/19]. 2019 [cited 2021 Jul 11]. https://www.cefas.co.uk/international-database-onaquatic-animal-diseases/abstract/ ?id=1938

11. Government of Canada. Fact sheet-infectious hypodermal and haematopoitic necrosis. 2019 [cited 2021 Jul 11].

https://inspection.canada.ca/animal-health/aquaticanimals/diseases/immediately-notifiable/infectioushypodermal-and-haematopoitic-necrosis/eng/1562271424092/ 1562271424389\#shr-pg0

12. Tang KFJ, Lightner DV. Infectious hypodermal and hematopoietic necrosis virus (IHHNV)-related sequences in the genome of the black tiger prawn Penaeus monodon from Africa and Australia. Virus Res. 2006;118:185-91. https:/ / doi.org/10.1016/j.virusres.2006.01.003

13. Tang KFJ, Navarro SA, Lightner DV. PCR assay for discriminating between infectious hypodermal and hematopoietic necrosis virus (IHHNV) and virus-related sequences in the genome of Penaeus monodon. Dis Aquat Organ. 2007;74:165-70. https://doi.org/10.3354/dao074165

14. Durand SV, Lightner DV. Quantitative real time PCR for the measurement of white spot syndrome virus in shrimp. J Fish Dis. 2002;25:381-9. https://doi.org/10.1046/ j.1365-2761.2002.00367.x

15. Aranguren LF, Tang KFJ, Lightner DV. Quantification of the bacterial agent of necrotizing hepatopancreatitis (NHP-B) by real-time PCR and comparison of survival and NHP load of two shrimp populations. Aquaculture. 2010;307:187-92. https://doi.org/10.1016/j.aquaculture. 2010.07.022

16. Tang KFJ, Pantoja CR, Redman RM, Han JE, Tran LH, Lightner DV. Development of in situ hybridization and PCR assays for the detection of Enterocytozoon hepatopenaei (EHP), a microsporidian parasite infecting penaeid shrimp. J Invertebr Pathol. 2015;130:37-41. https:/ / doi.org/10.1016/ j.jip.2015.06.009 
17. Han JE, Tang KF, Tran LH, Lightner DV. Photorhabdus insectrelated (Pir) toxin-like genes in a plasmid of Vibrio parahaemolyticus, the causative agent of acute hepatopancreatic necrosis disease (AHPND) of shrimp. Dis Aquat Organ. 2015;113:33-40. https://doi.org/10.3354/dao02830

18. Aranguren LF, Tang KFJ, Lightner DV. Protection from yellow head virus (YHV) infection in Penaeus vannamei pre-infected with Taura syndrome virus (TSV). Dis Aquat Organ. 2012;98:185-92. https:// doi.org/10.3354/dao02448

19. Tang KFJ, Wang J, Lightner DV. Quantitation of Taura syndrome virus by real-time RT-PCR with a TaqMan assay. J Virol Methods. 2004;115:109-14. https:// doi.org/10.1016/ j.jviromet.2003.09.021

20. Andrade TPD, Srisuvan T, Tang KFJ, Lightner DV. Real-time reverse transcription polymerase chain reaction assay using TaqMan probe for detection and quantification of infectious myonecrosis virus (IMNV). Aquaculture. 2007;264:9-15. https://doi.org/10.1016/j.aquaculture. 2006.11.030

21. Robles-Sikisaka R, Bohonak AJ, McClenaghan LR Jr, Dhar AK. Genetic signature of rapid IHHNV (infectious hypodermal and hematopoietic necrosis virus) expansion in wild Penaeus shrimp populations. PLoS One. 2010;5:e11799. https:/ / doi.org/10.1371/journal.pone.0011799

22. Kearse M, Moir R, Wilson A, Stones-Havas S, Cheung M, Sturrock S, et al. Geneious Basic: an integrated and extendable desktop software platform for the organization and analysis of sequence data. Bioinformatics. 2012;28: 1647-9. https://doi.org/10.1093/bioinformatics/bts199

23. Altschul SF, Gish W, Miller W, Myers EW, Lipman DJ. Basic local alignment search tool. J Mol Biol. 1990;215:403-10. https:/ / doi.org/10.1016/S0022-2836(05)80360-2

24. Tamura K, Nei M. Estimation of the number of nucleotide substitutions in the control region of mitochondrial DNA in humans and chimpanzees. Mol Biol Evol. 1993;10:512-26.

25. Kumar S, Stecher G, Tamura K. MEGA7: molecular evolutionary genetics analysis version 7.0 for bigger datasets. Mol Biol Evol. 2016;33:1870-4. https:/ / doi.org/10.1093/ molbev/msw054

26. Kaufmann B, Bowman VD, Li Y, Szelei J, Waddell PJ, Tijssen P, et al. Structure of Penaeus stylirostris densovirus, a shrimp pathogen. J Virol. 2010;84:11289-96. https:/ / doi.org/10.1128/JVI.01240-10

27. Nunan LM, Poulos BT, Lightner DV. Use of polymerase chain reaction for the detection of infectious hypodermal and hematopoietic necrosis virus in Penaeid shrimp. Mar Biotechnol (NY). 2000;2:319-28. https://doi.org/10.1007/ s101260000003

28. Saksmerprome V, Jitrakorn S, Chayaburakul K, Laiphrom S, Boonsua K, Flegel TW. Additional random, single to multiple genome fragments of Penaeus stylirostris densovirus in the giant tiger shrimp genome have implications for viral disease diagnosis. Virus Res. 2011;160:180-90. https://doi.org/ 10.1016/j.virusres. 2011.06.010

29. World Organisation for Animal Health (OIE). Infection with infectious hypodermal and haematopoietic necrosis virus. In: Manual of diagnostic tests for aquatic animals, 4th ed. Paris, France: Office International des Epizooties; 2017. p. 1-18.

30. Senapin S, Phewsaiya K, Briggs M, Flegel TW. Outbreaks of infectious myonecrosis virus (IMNV) in Indonesia confirmed by genome sequencing and use of an alternative RT-PCR detection method. Aquaculture. 2007;266:32-8. https://doi.org/10.1016/j.aquaculture.2007.02.026

31. Dhar AK, Lakshman DK, Amundsen K, Robles-Sikisaka R, Kaizer KN, Roy S, et al. Characterization of a Taura syndrome virus isolate originating from the 2004 Texas epizootic in cultured shrimp. Arch Virol. 2010;155:315-27. https:/ / doi.org/10.1007/s00705-009-0584-5

32. Chaijarasphong $\mathrm{T}$, Thammachai $\mathrm{T}$, Itsathitphaisarn $\mathrm{O}$, Sritunyalucksana K, Suebsing R. Potential application of CRISPR-Cas12a fluorescence assay coupled with rapid nucleic acid amplification for detection of white spot syndrome virus in shrimp. Aquaculture. 2019;512:734340. https:/ / doi.org/10.1016/j.aquaculture.2019.734340

33. Sullivan TJ, Dhar AK, Cruz-Flores R, Bodnar AG. Rapid, CRISPR-based, field-deployable detection of white spot syndrome virus in shrimp. Sci Rep. 2019;9:19702. https://doi.org/10.1038/s41598-019-56170-y

34. Lightner V. Biosecurity in shrimp farming: pathogen exclusion through use of SPF stock and routine surveillance. J World Aquacult Soc. 2005;36:230-48. https://doi.org/ 10.1111/j.1749-7345.2005.tb00328.x

Address for correspondence: Arun K. Dhar, Aquaculture Pathology Laboratory, School of Animal and Comparative Biomedical Sciences, Bldg 90, The University of Arizona, 1117 E Lowell St, Tucson, AZ 85721, USA; email: adhar@email.arizona.edu 